\title{
Use of the SWAT model for estimating reservoir volume in the Upper Navet watershed in Trinidad
}

\author{
Sharlene L. Beharry ${ }^{1} \cdot$ Donald Gabriels $^{2} \cdot$ Deyanira Lobo $^{3} \cdot$ Deanesh Ramsewak $^{4} \cdot$ Ricardo M. Clarke $^{1}$
}

Received: 29 September 2020 / Accepted: 12 January 2021 / Published online: 20 January 2021

(C) The Author(s) 2021 OPEN

\begin{abstract}
In tropical small islands the application of hydrological modelling is challenged by the scarcity of input data. Using insitu and statistically estimated data, a hydrological model was calibrated and validated for the Upper Navet watershed in Trinidad, a small Caribbean island. The model was built using the soil water assessment tool (SWAT). The sensitivity analysis, calibration and validation were performed in SWAT calibration and uncertainty program (SWAT-CUP) using sequential uncertainty fitting (SUFI-2). The results revealed that for the estimated volume of water flowing into the reservoir (Flow_In) there were six sensitive parameters. To estimate the reservoir volume (Res_Vol), a modification of only the effective hydraulic conductivity was required. The model's performance for the Flow_In validation showed acceptable values $\left(R^{2}=0.91\right.$ and $\left.\mathrm{NSE}=0.81\right)$. The uncertainty analysis indicated lower than recommended values for both the $R$-factor (0.46) and $P$-factor (0.31). For Res_Vol, the model's validation performance indicated acceptable values $\left(R^{2}=0.72\right.$ and NSE $=0.70$ ) and the $P$ - and $R$-factors were 0.80 and 0.64 , respectively. Based on the statistical metrics, the uncertainty for the Res_Vol was regarded as reasonable. However, care must be taken with the model's use in the dry season, as the simulated Flow_In was generally over-predicted. A second validation of the model was performed for the reservoir under different negative (removal) and positive (addition) water amounts which confirmed the model's ability to estimate the Res_Vol. The hydrological model established can therefore serve as a useful tool for water managers for the estimation of the Res_Vol at the Navet reservoir.
\end{abstract}

Keywords Scarcity of data $\cdot$ Reservoir modelling $\cdot$ Volume estimation $\cdot$ Sensitivity analysis $\cdot$ SWAT-CUP $\cdot$ Caribbean

\section{Introduction}

Changes in weather patterns, water demand and operations at a reservoir scale may cause a shift in the local water balance. Since the 1980s, water use has increased about $1 \%$ per year globally and the trend is expected to continue until 2050 due to an increase demand for water from the industrial and domestic sectors [1]. For sustainable development of any country, the management of the available water is essential. Therefore, the understanding of the hydrology at the watershed scale and the estimation of the available water are key parameters which decision makers can use.

In small islands, the freshwater supply has always presented challenges and there is a gap of information within countries [2]. In the Caribbean, a region of small island states, the available water resources vary spatially and are influenced by factors such as climate, geology and topography [3], with climate being the most variable. Of great concern are the future projections of climate change and

$\triangle$ Sharlene L. Beharry, sharlenelata@yahoo.com; Donald Gabriels, donaldgabriels@gmail.com; Deyanira Lobo, lobo.deyanira@gmail.com; Deanesh Ramsewak, deanesh.ramsewak@utt.edu.tt; Ricardo M. Clarke, ricardo.clarke@sta.uwi.edu | 1 Department of Physics, The University of the West Indies, St Augustine, Trinidad and Tobago. ${ }^{2}$ Department of Soil Management, Ghent University, Ghent, Belgium. ${ }^{3}$ Agronomy Faculty, Universidad Central de Venezuela, Caracas, Venezuela. ${ }^{4}$ Centre for Maritime and Ocean Studies, The University of Trinidad and Tobago, Chaguaramas Campus, Chaguaramas, Trinidad and Tobago. 
their potential impacts on these islands. For example, for the southern-most small island in the region, Trinidad, it is projected that the area would receive less intense rainfall and more dry days [4] and it is expected to become drier and warmer [5]. In the evaluation of how changes in climate conditions affect available water resources, hydrological modelling has been a valuable tool [6-10]. The prerequisites for the modelling process are the calibration and validation of the model, for the model's specified use. This research, therefore, focuses on the sensitivity analysis, the calibration and validation of a hydrological model for a surface water reservoir under different water removal and addition amounts, in a small tropical watershed, in the Caribbean island of Trinidad.

For the tropical island of Trinidad, the annual rainfall varies from 1300 to $2800 \mathrm{~mm}$ [11], with some areas receiving more precipitation than others. The water demand on the island from all sectors is supplied from a combination of surface water, ground water, and desalinated water, with surface water supplying the highest percentage of water [12]. Surface water in Trinidad comprises of intakes from rivers and three reservoirs. The reservoirs are the main source of water in the dry season and during the wet season the reservoir levels are recharged to the maximum limit. Acknowledging the projections of Campbell et al. [4] and McLean et al. [5] as well as the rainfall spatial variability in Trinidad, it is imperative that the individual reservoirs be modelled to aid in climatic impact assessments which would provide information required for mitigation strategies.

In recent years, the Soil Water Assessment Tool (SWAT) a physically based, continuous time model which is computationally efficient, uses readily available inputs and allows for long-term impacts. SWAT has been successfully utilized by many researchers [13]. Some studies that used SWAT and calibrated reservoir parameters for different applications include; Zanin et al. [14] with the evaluation of the calibrations of the water and sediment balance in Brazil; Carvalho-Santos et al. [15] assessing the implications of climate change in the reservoir planning in Portugal; $\mathrm{Wu}$ and Chen [16] using SWAT in the evaluation of the performance of a reservoir operation scheme in China, and Vale and Holman [17] employing SWAT to improve the understanding of the hydrological functioning of the lake system in the UK.

Noting the research gap in acknowledging the heterogeneity and complexity of small island states [2], and the lack of geographic homogeneity [18], it is difficult to make generalized observations about water resources for the Caribbean region as a whole. One of the reasons for the research gap may be due to large percentages of missing data and/or limited available data which are required inputs for physics-based hydrological models.
In the Caribbean, focusing on the issue of water security, Cashman [18] reported that there is a lack of data and challenges in accessing available information. The lack of data is not unique to the Caribbean, as other regions also have limited available hydro-meteorological data. Some examples are in Central America [19], Himalayan regions [20] and Ethiopia [21]. Addressing the issue of limited data for the calibration of hydrological models for catchments, Mengistu et al. [22] listed three methods to deal with the paucity of data. These included (1) regionalization approach, (2) crop yield data, and (3) remote sensing data. In this study, where there were unavailable suitable datasets, statistical relationships were established using data sourced from the local water resource agency. They were used with a physics-based model to generate required input values for the calibration and validation processes.

For Trinidad, acknowledging the possibility of changes in the future climate changes $[4,5]$ and taking into account the role reservoirs often play in mitigating water supply problems [15], this study aims to provide information required to model the reservoir future capacity of the upper Navet watershed in Trinidad. Considering that the main purpose of the reservoir is water extraction to meet water demands, a scenario representing an increased water demand from the reservoir was studied for an additional validation. Thus, the calibrated model may provide useful information for the management and planning of water resources at the Navet Reservoir. The aim of the research was to establish a hydrological model for the Navet Reservoir to estimate the volume of water (Res_Vol). Therefore, the objectives were (1) to calibrate and (2) to validate, the established Navet hydrological model.

\section{Data and methods}

\subsection{Description of study area}

Trinidad is part of the Republic of Trinidad and Tobago, a twin island state located between $10^{\circ} \mathrm{N}$ and $11.5^{\circ} \mathrm{N}$ latitude, and between $60^{\circ} \mathrm{W}$ and $62^{\circ} \mathrm{W}$ longitude in the Caribbean Sea. The area of focus, the Upper Navet watershed is the home of the second-largest reservoir, the Navet Reservoir, in Trinidad (Fig. 1). The watershed is located in the Central Range which has an irregular ridge that extends diagonally across the island and consists of rounded hillridges with a maximum elevation of $307 \mathrm{~m}$ at Tamana Hill on the eastern end of the range [23]. These ridges are separated by ravines containing fast flowing streams fed by springs which generally disappear during the dry season [23].

The climate of Trinidad is classified as tropical maritime from January to May referred to as the dry season, 

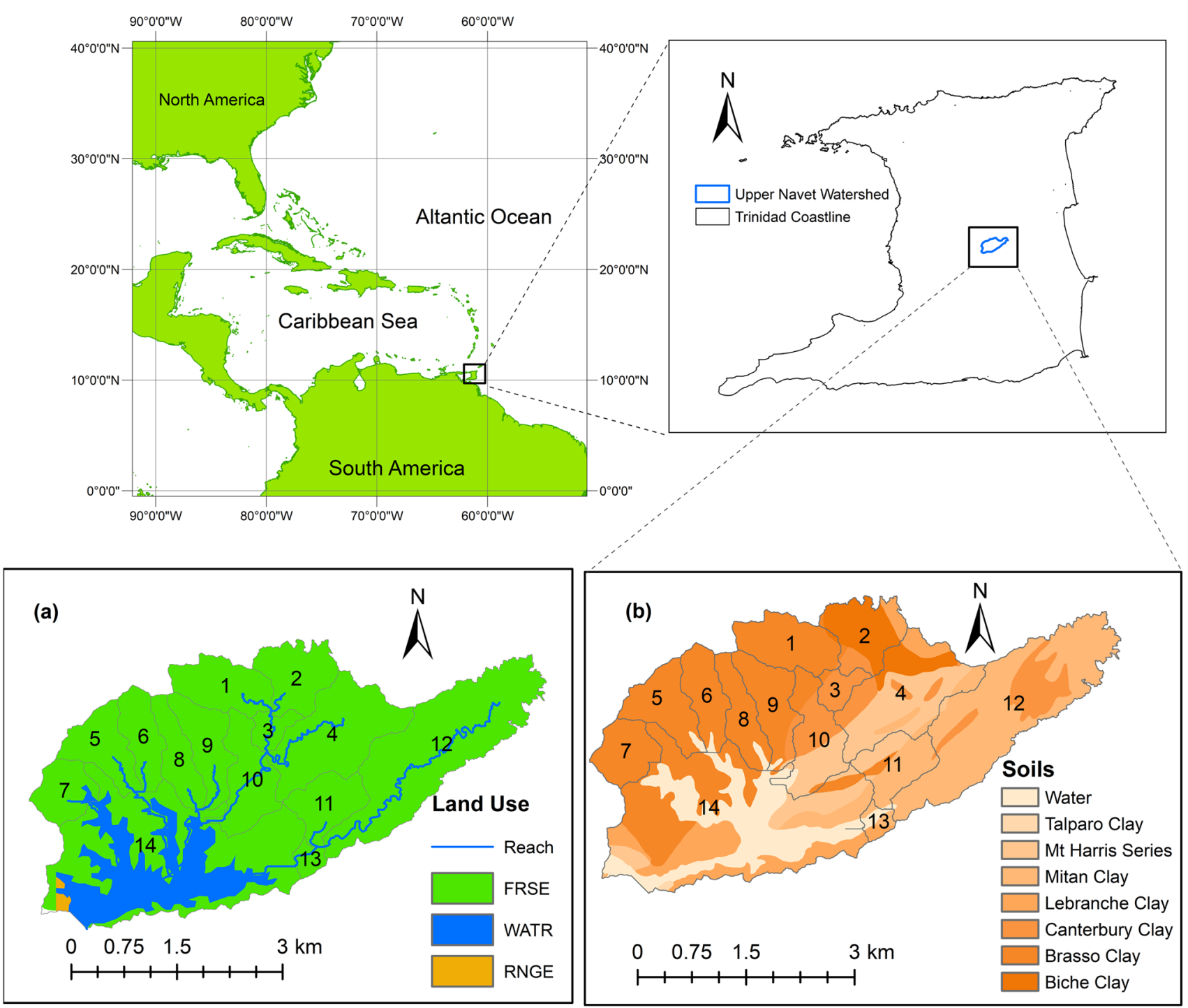

Fig. 1 Location of Trinidad and the Upper Navet Watershed. a Land Use where FRSE is evergreen forest in green, WATR is water in blue and RNGE is rangeland is yellow; $\boldsymbol{b}$ soil classification based on the local soil names

and by a modified moist equatorial climate from June to December, the wet season [24]. The average annual rainfall at the Navet Reservoir for the period 1979 to 2017 was $2234.2 \mathrm{~mm}$, seasonally $21 \%$ of the precipitation occurs in the dry season and $79 \%$ in the wet season.

The Upper Navet watershed has three different land coverages; evergreen forest $(87 \%)$, water (12\%) and grasses (1\%) with the percentage of each coverage in parentheses (Fig. 1a). There are seven different soils which cover the area; Brasso Clay, Biche Clay, Canterbury Clay, L'Ebranche Clay, Mitan Clay, Mt Harris Series, and Talparo Clay, with Brasso Clay being $34 \%$ of the total area (Fig. $1 \mathrm{~b}$ ).

The total area of Trinidad is $4862 \mathrm{~km}^{2}$. The Upper Navet catchment area covers $18.13 \mathrm{~km}^{2}$ with an effective drainage area of $15.54 \mathrm{~km}^{2}$ and an approximate reservoir area of $2.59 \mathrm{~km}^{2}$ [25]. The Navet Dam consists of two impoundments; the upper reservoir and a lower reservoir located $2.5 \mathrm{~km}$ away [26]. The upper dam has an irregular shape with a capacity of 19.1 million $\mathrm{m}^{3}$ of water [27]. The dam was commissioned in 1962 with an output of $27500 \mathrm{~m}^{3}$ water per day, first extended in 1966 to an output of $55,000 \mathrm{~m}^{3}$ per day, followed by a second expansion in 1976 resulting in an output of $86,400 \mathrm{~m}^{3}$ per day [27]. The second expansion was possible due to the development of the Lower Dam, where water from the lower reservoir is pumped into the upper reservoir. Therefore, water flowing into the Upper Reservoir comprises of the water pumped into the dam and the natural runoff via streams which flow near the hillsides at Mt. Tamana, Brasso Piedra and Chataigne. The upper reservoir has one spillway so that water 
is only allowed to flow out downstream when the reservoir reaches the threshold water level at approximately $95 \mathrm{~m}$. Thus, in this study, the spillway was considered as an emergency spillway.

\subsection{Model description}

SWAT is a model for the river basin or watershed scale which can be applied to a single watershed, such as the Upper Navet Watershed. SWAT allows for different physical processes to be simulated. In establishing a simulation, SWAT relies on climatological, hydrological, geographical, and management data of the watershed. In this study, the simulation was set up in an ArcGIS 10.3.1 environment using SWAT2012.

SWAT was built on the foundation of the water balance, which is used as the basis of any process investigated in a watershed. The main components in the water balance are the land and the water phases. This study takes into consideration the water or routing aspects of a reservoir. The monthly water balance (Eq. 1) for reservoirs includes flow in and out of the reservoir, rainfall on the surface, evaporation, seepage from the reservoir bottom, and diversions [13].
Climatological data for the period 1979-2000 (22 years) and hydrological data were entered into the model. Details of the datasets are presented in "Data" section. In the simulation step, the first 5 years of the 22-year period were designated as the warmup period which was used to establish the initial conditions of the model. The temporal time scale of the model output was set to a monthly basis in order to match the available data for calibration.

\subsection{Data}

The geographical data were in the form of geographic information system (GIS) data which comprised of landuse and soil shapefiles, obtained from the Geomatics Department, Faculty of Engineering, The University of the West Indies, St. Augustine Campus. Additionally, the $1 \mathrm{~m}$ DEM was created from 2014 light detection and ranging (LIDAR) data accessed from the Surveys and Mapping Division of the Ministry of Agriculture, Land and Fisheries, Trinidad and Tobago.

The historical climatological parameters required were daily rainfall, daily maximum and minimum temperatures, monthly relative humidity, solar radiation, and wind speed served as prerequisites for the weather generator and the

$V=V_{\text {stored }}+V_{\text {flowin }}-V_{\text {flowout }}+V_{\text {pcp }}-V_{\text {evap }}-V_{\text {seep }} \quad$ Neitsch et al. [13]

where $V$ is the volume of water in the impoundment at the end of the month ( $\mathrm{m}^{3}$ water), $V_{\text {stored }}$ is the volume of water stored in the reservoir at the beginning of the month $\left(\mathrm{m}^{3}\right.$ water), $V_{\text {flowin }}$ is the volume of water entering the reservoir during the month $\left(\mathrm{m}^{3}\right.$ water), $v_{\text {flowout }}$ is the volume of water flowing out of the reservoir during the month $\left(\mathrm{m}^{3}\right.$ water), $V_{p c p}$ is the volume of precipitation falling on the reservoir during the month ( $\mathrm{m}^{3}$ water), $V_{\text {evap }}$ is the volume of water removed from the reservoir by evaporation during the month ( $\mathrm{m}^{3}$ water), and $V_{\text {seep }}$ is the volume of water lost from the reservoir by seepage $\left(\mathrm{m}^{3}\right.$ water).

The setup of the Navet hydrological model included a digital elevation model (DEM) of $1 \mathrm{~m}(\mathrm{~m})$ spatial resolution that was used to define the streams. A point source was added to represent the additional water from the lower reservoir, then the watershed was delineated, followed by the calculation of the sub-basin and the addition of the Navet Reservoir to the model. The next step consisted of dividing the watershed into sub-basins and then into hydrologic response units (HRUs) which were defined by the dominant Land Use, soil, and slope. HRUs represent areas of unique Land Use and soil combinations [28] that were built based on the in-situ landuse and soil data.

In this study, there were three different landuse types, seven different soil types, and two slope classes. weather station inputs in SWAT.

For the weather generator, five years of Navet daily rainfall data were used, after considering the spatial variation across the island along with correlations with other available in situ datasets and global datasets. For temperature and relative humidity data, the datasets from the University of the West Indies, St Augustine Field Station (UFS) were utilized. The Piarco (MET) monthly solar radiation data was the only available dataset in the country, and for wind speed the Navet in-situ monthly wind speed data during for 1969-1987 were used.

For the weather station inputs data, in-situ monthly rainfall data for Navet, for the period 1979 to 2000 were converted to daily data. The conversion was achieved by utilizing a stand-alone tool, Monthly to Daily Weather Convertor (MODAWEC) [29]. The daily temperature data from UFS, and data simulated from the weather generator were used for the relative humidity, solar radiation and wind speed.

The hydrological data included the general characteristics such as the surface area, sediment concentration, the volume of water, and the river discharge and/ or runoff of rainfall in the reservoir. The general surface area of the Navet Reservoir is $3.24 \mathrm{~km}^{2}$ [27]. The change in sediment volume is negligible, as the vulnerability 
of the watersheds to land degradation was low [30]. The volume of water in the reservoir (Res_Vol) was estimated from the lake levels. In this study, the estimated volume of water flowing into the reservoir (Flow_In) comprises the calculated runoff plus the water entering the reservoir from the lower impoundment. Flow In estimated using a multiple regression model, with the independent variables being the reservoir storage level at the end of the month, the monthly rainfall, and the monthly mean discharge in the river downstream of the reservoir. Water entering the reservoir from outside the watershed was included as a point source before the delineation of the watershed during the model setup. The management data included how water was released over the spillway and the average daily principal spillway release rate. In this study, the outflow is uncontrolled, and the estimated average daily principal spillway release rate was $0.6 \mathrm{~m}^{3} \mathrm{~s}^{-1}$.

\subsection{Sensitivity analysis, calibration, validation and uncertainty}

After the initial model setup, the sensitivity, calibration, validation and uncertainty analyses of the model were executed in the SWAT Calibration and Uncertainty Programs (SWAT-CUP) software package.

\subsubsection{Sensitivity analysis}

The sensitivity analyses aim to gain a better understanding of the relative effects of parameters on the model output. SWAT-CUP enables the user to identify parameters that significantly influence the variable being calibrated, in this case, first Flow_In and then Res_Vol. The identified parameters were those with the greatest variance compared with the calibrated parameters. There are two main approaches to the sensitivity analysis: one at a time approach and the other the global approach. In this study, the global sensitivity approach was selected as it produces more reliable results [31]. The sensitive parameters were identified by calculating multiple regression using the Latin hypercube generated against the objective function value, using Eq. 2.

$g=\alpha+\sum_{i=1}^{m} \beta_{i} b_{i}$

where $g$ is the objective function value; $a$ is the regression constant; $\beta$ is the coefficient of parameters; $b$ is a parameter generated by the Latin hypercube method [32]; $\mathrm{m}$ is the number of parameters.

For our study area, there was not a known set of parameters. Therefore, based on research using SWAT from Jamaica [33], Cuba [34], Brazil [35], Hawaii [36], Portugal [15] and China [32], 16 parameters related to runoff were selected for reservoir inflow (Table 1). To evaluate

Table 1 List of parameters with the method of modifying parameters and the default ranges used in the sensitivity analysis

\begin{tabular}{|c|c|c|c|c|c|}
\hline \multirow{2}{*}{$\frac{\text { No. }}{1}$} & \multirow{2}{*}{ Method } & \multirow{2}{*}{$\begin{array}{l}\text { Parameter name (description) } \\
\text { ESCO (Soil evaporation compensation factor) }\end{array}$} & \multirow{2}{*}{$\begin{array}{l}\text { File Ext } \\
\text { hru }\end{array}$} & \multicolumn{2}{|c|}{ Initial range } \\
\hline & & & & 0 & 1 \\
\hline 2 & $v$ & ALPHA_BNK (Baseflow alpha factor for bank storage in days) & rte & 0 & 1 \\
\hline 3 & $v$ & $\mathrm{CH} \_\mathrm{K} 2$ (Effective hydraulic conductivity in main channel alluvium in $\mathrm{mm} / \mathrm{hr}$ ) & rte & -0.01 & 100 \\
\hline 4 & $v$ & GW_DELAY (Groundwater delay time in days) & gw & 0 & 45 \\
\hline 5 & $v$ & ALPHA_BF (Baseflow alpha factor in days) & gw & 0 & 1 \\
\hline 6 & $v$ & CH_N2 (Manning's " $n$ " value for the main channel) & rte & -0.01 & 0.3 \\
\hline 7 & $r$ & CN2 (SCS runoff curve number) & mgt & -0.1 & 0.1 \\
\hline 8 & $v$ & EPCO (Plant uptake compensation factor) & hru & 0 & 1 \\
\hline 9 & $r$ & OV_N (Manning's " $n$ " value for overland flow) & hru & -0.2 & 0.2 \\
\hline 10 & $v$ & $\begin{array}{l}\text { REVAPMN (Threshold depth of water in the shallow aquifer for "revap" to occur in } \\
\mathrm{mmH}_{2} \mathrm{O} \text { ) }\end{array}$ & gw & 0 & 50 \\
\hline 11 & $v$ & SURLAG (Surface runoff lag time) & bsn & 0.05 & 12 \\
\hline 12 & $r$ & SOL_K (1) (Saturated hydraulic conductivity in $\mathrm{mm} / \mathrm{hr}$ ) & sol & -0.2 & 0.2 \\
\hline 13 & $r$ & SOL_BD (1) (Moist bulk density in $\mathrm{Mg} / \mathrm{m}^{3}$ ) & sol & -0.2 & 0.2 \\
\hline 14 & $r$ & $\begin{array}{l}\text { GWQMN (Threshold depth of water in the shallow aquifer required for return } \\
\text { flow to occur in } \mathrm{mmH}_{2} \mathrm{O} \text { ) }\end{array}$ & gw & -0.1 & 0.1 \\
\hline 15 & $r$ & SOL_AWC (1) (Available water capacity of the soil layer in $\mathrm{mm} / \mathrm{mm}$ ) & sol & -0.2 & 0.2 \\
\hline 16 & $r$ & GW_REVAP (Groundwater "revap" coefficient) & gw & -0.1 & 0.1 \\
\hline
\end{tabular}

$v$ represents the existing parameter to be replaced by a given value and $r$ is the existing parameter value multiplied by $(1+a$ given value) 
the significance of the relative sensitivity, the $t$-stat and $p$-value were utilized. The $t$-stat provides a measure of sensitivity and the $p$-value determines the significance of the sensitivity. The larger absolute $t$-stat signifies greater sensitivity and the closer to zero the $p$-value, the higher significance [31]. The most sensitive parameters were identified after each iteration, during the calibration process.

\subsubsection{Calibration and validation}

There are five different calibration methods in SWAT-CUP: (1) sequential uncertainty fitting version 2 (SUFI-2), (2) generalized likelihood uncertainty estimation (GLUE), (3) parameter solution (ParaSoL), (4) Markov chain Monte Carlo (MCMC) and (5) particle swarm optimization (PSO). According to Wu and Chen [37], SUFI-2 provides a good accuracy and has the ability to capture the observed data with small uncertainties. Furthermore, Molina-Navarro et al. [38] noted that SUFI-2 requires a lower number of model runs to achieve a satisfactory solution. Additionally, Abbaspour [39] stated that the uncertainty result is expressed as a range and accounts for all sources of uncertainties, that is, parameter, conceptual, model, and inputs. After considering the SUFI-2 advantages compared with GLUE and ParaSol, the SUFI-2 method was selected for calibration and validation.

Calibration was performed in the reservoir module of SWAT-CUP based on the available data. In view of the model's initialization period 1979-1983, the periods of calibration and validation for Flow_In were 1984-1990 (7 years) and 1992, 1993, and 1995 (3 years), respectively. For Res Vol, the calibration period was 1984-1993 (10 years), with 1994-2000 (7 years) as the validation period.

Using data for the period 1979-2000, the Navet hydrological model was built, calibrated and validated. Considering a scenario of an increased demand for water from the reservoir, that is, a greater volume of water extracted (WURESN) as in the case during 2001-2010, the model's performance was evaluated. Therefore, using the new WURESN and new volume of water entering the point source data, for the period 2001-2010, the model's ability to estimate Res_Vol under a scenario of increased water demand was investigated, referred as a 2 nd validation.
After each iteration in the calibration process, the ranges of the parameters were adjusted, ensuring that values remain in the physical range and at the same time narrowing the range based on the new parameter ranges suggested by SWAT-CUP. After achieving the best model performance, the range of calibrated parameters was used together with an independent time period in another iteration to validate the model.

\subsubsection{Evaluation of model performance}

In the evaluation of the model performance the following quantitative statistics were used; the coefficient of determination $\left(R^{2}\right)$, the Nash-Sutcliffe Coefficient (NSE), percent bias (PBIAS) and root mean square error-observations standard deviation ratio (RSR). The performance ratings according to Moriasi et al. [40] were described as very good, good, satisfactory or unsatisfactory (Table 2 ). These have been used as the goodness of fit indicators for best simulation by [33, 35, 36, 41-46].

$R^{2}$ is a standard regression technique that determines the strength of the linear relationship between simulated and measured data [40]. It also describes the proportion of the variance in the measured data explained by the model and is calculated using

$R^{2}=\frac{\left[\sum_{i}\left(Q_{i}^{\text {obs }}-Q_{i}^{\text {obs, mean }}\right)\left(Q_{i}^{\text {sim }}-Q_{i}^{\text {sim, mean }}\right)\right]^{2}}{\sum_{i}\left(Q_{i}^{\text {obs }}-Q_{i}^{\text {obs, mean }}\right)^{2} \sum_{i}\left(Q_{i}^{\text {sim }}-Q_{i}^{\text {sim, mean }}\right)^{2}} \quad$ Abbaspour [39]

$R^{2}$ values range from 0 to 1 which represent the trend between the observed data and the simulated, with higher values indicating less error variance [40] and better model performance. Generally, values greater than 0.5 are considered acceptable $[40,43]$. It is also noted that Santhi et al. [47] used a value greater than 0.5 , that is, $R^{2} \geq 0.6$ as satisfactory. In this study, the model performance range of values from Moriasi et al. [40] was adopted, as it is widely used in the literature.

The NSE is a normalized statistic that determines the relative magnitude of the residual variance compared to the measured data variance Moriasi et al. [40]. The NSE
Table 2 General performance rating for hydrologic models $\left(R^{2}\right.$, NSE, PBIAS and RSR based on Moriasi et al. [40])

\begin{tabular}{lllll}
\hline & Very good & Good & Satisfactory (acceptable) & Unsatisfactory \\
\hline$R^{2}$ & & & $>0.50$ & $\leq 0.50$ \\
NSE & $0.75 \leq \mathrm{NSE} \leq 1.00$ & $0.65 \leq \mathrm{NSE} \leq 0.75$ & $0.5 \leq \mathrm{NSE} \leq 0.65$ & $\mathrm{NSE} \leq 0.50$ \\
$\mathrm{PBIAS}$ & $\mathrm{PBIAS}< \pm 10$ & $\pm 10 \leq \mathrm{PBIAS} \leq \pm 15$ & $\pm 15 \leq \mathrm{PBI} \mathrm{AS} \leq \pm 25$ & $\mathrm{PBIAS} \geq \pm 25$ \\
$\mathrm{RSR}$ & $0.00 \leq \mathrm{RSR} \leq 0.50$ & $0.50 \leq \mathrm{RSR} \leq 0.60$ & $0.60 \leq \mathrm{RSR} \leq 0.70$ & $\mathrm{RSR}>0.70$ \\
\hline
\end{tabular}

$R^{2}$ is the coefficient of determination, NSE is the Nash-Sutcliffe Coefficient, PBAIS is the percent bias, RSR is RMSE-observations standard deviation ratio 
indicates how well the plot of observed versus simulated data fits the one to one ratio and is determined by

NSE $=1-\frac{\sum_{i}^{n}\left(Q_{i}^{\text {obs }}-Q_{i}^{\text {sim }}\right)^{2}}{\sum_{i}^{n}\left(Q_{i}^{\text {obs }}-Q_{i}^{\text {mean }}\right)^{2}}$

where $Q$ is the variable (e.g. discharge); $i$ is the ith observed or simulated data; obs is the observed; sim is the simulated, and mean is the observed average. NSE values range from $-\infty$ to 1 , however, values between 0 and 1 are generally considered acceptable level performance [40], as values less than or equal to zero indicates that the mean observed value is a better predictor than the simulated value.

In the evaluation for the error index of the model the percent bias (PBIAS) and the root mean square error (RMSE) observations standard deviation ratio (RSR) were determined. Percent bias (PBIAS) measures the average tendency of the simulated data to be larger or smaller than their observed counterparts [40]. It is calculated by

PBIAS $=\left[\frac{\sum_{i=1}^{n}\left(Q_{i}^{\text {obs }}-Q_{i}^{\text {sim }}\right) \times(100)}{\sum_{i=1}^{n}\left(Q_{i}^{\text {obs }}\right)}\right]$

Ideally when the PBIAS is 0.0 , that is an accurate model simulation. Positive values indicate model underestimation bias, and negative values indicate overestimation bias [48].

The RSR is the ratio of the root mean square error (RMSE) and the observation standard deviation (STDEV ${ }_{\text {obs }}$ ) [40] and is calculated by

$\mathrm{RSR}=\frac{\mathrm{RMSE}}{\text { STDEV }_{\text {obs }}}=\frac{\left[\sqrt{\sum_{i=1}^{n}\left(Q_{i}^{\text {obs }}-Q_{i}^{\text {sim }}\right)^{2}}\right]}{\left[\sqrt{\sum_{i=1}^{n}\left(Q_{i}^{\text {obs }}-Q_{i}^{\text {mean }}\right)^{2}}\right]}$

The values of RSR vary from a perfect model, that is, $\mathrm{RSR}=0$ when the RMSE is zero to a large positive value [40]. Moriasi et al. [40] recommended for a monthly time step that values greater than 0.7 as unsatisfactory. The upper limit can go to infinity and these large values would imply unsatisfactory performance.

\subsubsection{Uncertainty}

Uncertainties in watershed models can be large and can be divided into conceptual, input, and parameter uncertainties. The SUFI-2 method accounts for all sources of uncertainty [39] and is expressed in the $95 \%$ prediction uncertainty (95PPU) model output. The 95PPU is not a single value but is expressed in a range. The $P$-factor and $R$-factor were utilized to achieve the best model results. The $P$-factor is the percentage of observed data while the
$R$-factor is the thickness in the 95PPU range. Ideally, the range should be small with most of the observed data within it. The recommended values for discharge are, a $P$-factor greater than 0.7 and a $R$-factor around 1 [39].

\section{Results and discussion}

This section presents the results and discusses the sensitivity analysis, calibration and validation of the SWAT model for Flow_In and the Res_Vol of the Upper Navet Reservoir. Additionally, the prediction uncertainty of the model is addressed.

\subsection{Sensitivity}

In the Upper Navet watershed, 16 parameters related to runoff were selected for the sensitivity analysis, calibration, and validation of the built model. In the first iteration, the SWAT default parameter ranges were used to represent the parameters' maximum and minimum values and the calibrated ranges are listed in Table 3. The most sensitive parameters identified, from the most to the least, based on the $t$ statistics were soil evaporation compensation factor (ESCO), baseflow alpha factor for bank storage (ALPHA BNK), effective hydraulic conductivity in main channel alluvium ( $\left.\mathrm{CH} \_\mathrm{K} 2\right)$, ground water delay time (GW_DELAY), baseflow alpha factor (ALPHA_BF), and Manning's " $n$ " value for the main channel ( $\left.\mathrm{CH} \_\mathrm{N} 2\right)$ (Table 3). This, therefore suggests that changes among these six parameters mostly influence the Flow_In into the Navet Reservoir.

Comparing the parameters' default values to the calibrated values, it was found that there were decreases in ESCO and GW_DELAY while there were increases in $\mathrm{CH}$ K2 , ALPHA_BF, and CH_N2. The decrease in the ESCO value from 0.95 to 0.36 allowed more water to be extracted from lower levels to meet the soil evaporative demands [49] and reduced the streamflow [50]. The GW_DELAY was reduced from 31 to 7.09, which would increase the baseflow in the model, also reported by Zanin et al. [14] as the parameter adjusts the time water moves through the soil profile to the shallow aquifer recharge [49]. The $\mathrm{CH}$ _K2 value indicates the measure of the rate of water loss from the channel to groundwater [45]. In this study, the initial value of CH_K2 was zero, which according to Arnold et al. [49] represented a continuous groundwater contribution to the rivers and the increase to 7.29 corresponds to river beds with sand and gravel mixture with high silt-clay content. This description of the effective hydraulic conductivity in the main channel alluvium relates well with the clay content in the channel and the texture of soils in the river valleys recognized as silty clay to clay in the Navet drainage area [25]. ALPHA_BF parameter affects the baseflow 
Table 3 List of parameters the calibrated ranges, the parameter fitted value, the $t$ stat and the $p$ value

\begin{tabular}{|c|c|c|c|c|c|c|}
\hline \multirow{2}{*}{$\frac{\text { Rank }}{1}$} & \multirow{2}{*}{$\begin{array}{l}\text { Parameter name } \\
\text { ESCO }\end{array}$} & \multicolumn{2}{|c|}{ Calibrated range } & \multirow{2}{*}{$\frac{\text { Fitted value }}{0.36}$} & \multirow{2}{*}{$\frac{t \text { stat }}{-23.70}$} & \multirow{2}{*}{$\frac{p \text { value }}{0.00}$} \\
\hline & & 0.16 & 0.37 & & & \\
\hline 2 & ALPHA_BNK & 0 & 0.13 & 0.00 & 12.59 & 0.00 \\
\hline 3 & $\mathrm{CH} \_\mathrm{K} 2$ & 0 & 17.48 & 7.29 & -7.97 & 0.00 \\
\hline 4 & GW_DELAY & 0.51 & 11.25 & 7.09 & -5.24 & 0.00 \\
\hline 5 & ALPHA_BF & 0.50 & 0.65 & 0.59 & 3.83 & 0.00 \\
\hline 6 & $\mathrm{CH} \_\mathrm{N} 2$ & 0.22 & 0.29 & 0.27 & -3.10 & 0.00 \\
\hline 7 & $\mathrm{CN} 2$ & -0.02 & 0.01 & -0.01 & 2.21 & 0.03 \\
\hline 8 & EPCO & 0.79 & 1 & 0.89 & 2.10 & 0.04 \\
\hline 9 & OV_N & -0.17 & -0.08 & -0.09 & -1.38 & 0.17 \\
\hline 10 & REVAPMN & 40.03 & 50 & 48.41 & -1.31 & 0.19 \\
\hline 11 & SURLAG & 9.74 & 12 & 10.35 & -1.04 & 0.30 \\
\hline 12 & SOL_K (1) & -0.25 & -0.15 & -0.21 & 1.04 & 0.30 \\
\hline 13 & SOL_BD (1) & 0.13 & 0.2 & 0.19 & -0.97 & 0.33 \\
\hline 14 & GWQMN & 0.7 & 0.1 & 0.09 & 0.94 & 0.35 \\
\hline 15 & SOL_AWC (1) & -0.16 & -0.07 & -0.15 & 0.90 & 0.37 \\
\hline 16 & GW_REVAP & -0.01 & 0.02 & 0.00 & 0.46 & 0.64 \\
\hline
\end{tabular}

and decreasing the value reduced the baseflow, while the surface runoff and the lateral flow were unaffected. In this study, the ALPHA_BF was increased from 0.05 to 0.59 which represents a moderate response, given that Arnold et al. [49] reported that values for ALPHA_BF for a slow response to recharge values vary from 0.1 to 0.3 and for a rapid response the values range from 0.9 to 1 . $\mathrm{CH}_{-} \mathrm{N} 2$ relates to the Manning's roughness coefficient for flow in the channels. The range of values for $\mathrm{CH}$ _N2 fell within the median roughness coefficient for natural streams, which is 0.05 to 0.10 [49]. ALPHA_BNK characterizes the bank storage recession curve and small values close to zero suggest steep recessions [49]. For the Upper Navet watershed both the default and calibrated values were close to zero.

As for the Res_Vol sensitivity analysis, calibration, and validation, the reservoir water balance equation (Eq. 1) was considered and only one parameter, Res_K was utilized. For the Navet hydrological model, it was found that the range of Res_K was 0.4 to 0.8 . Noting that the soils at the Navet Reservoir can also be described as silty clay to clay [25], and for a soil texture reported as predominantly clayey/very clayey, it was found that Res_K was 0.30 [14] and that the calibrated values appear reasonable.

\subsection{Model performance}

During the calibration process, two variables were considered but calibrated separately. Flow_In was first calibrated since the flow was reported as the main controlling variable [39]. Maintaining the Flow_In parameter ranges acquired during calibration, then, Res_Vol was calibrated. As stated in "Sensitivity analysis, calibration, validation and uncertainty" section, Flow_In was calibrated for 1984-1990 and validated for three years, 1992, 1993, and 1995. The Navet hydrological model calibration statistical metrics, $R^{2}, \mathrm{NSE}, \mathrm{PBIAS}$, and RSR were $0.89,0.84,-11.40$, and 0.40 , respectively (Table 4 ).

For the calibration period, the Flow_In statistical metrics (Table 2) based on Moriasi et al. [40] were acceptable and very good. For the validation period, the model performance was very good for NSE and RSR, and the error indices, $R^{2}$ and PBIAS were acceptable. Therefore, the Navet hydrological model captured the Flow_In reasonably in the Navet Reservoir. The graphical representation of the simulated and observed Flow_In for the reservoir calibration and validation periods are presented in Fig. 2a, together with the model's uncertainty in the grey band. The model's uncertainty 95PPU was evaluated using the $P$-factor and the $R$-factor. It was found that for the Navet hydrological model, the $P$-factor values were 0.42 and 0.31 for the calibration and validation phases, respectively. These values indicate that $42 \%$ of the observed Flow_In was enveloped by the 95PPU during the calibration and $31 \%$ during validation. Ideally, it would be desirable $100 \%$ of the observation in 95PPU; however, according to Abbaspour et al. [51], for discharge, a $P$-factor value greater than 0.7 and $\mathrm{R}$-factor less than 1.5, were recommended to be adequate; but, it depends on the scale of the project and available data [51]. For this present study, the $P$-factor values were lower than the suggested range as stated above, indicating higher than suggested model error. At the same time, the $R$-factor values fell within the acceptable range. Also, it was found that generally for the months with less precipitation, namely February, March, and April, the model overestimated the Flow_In. 
Table 4 Summary of the calibration and validation results for flow into the reservoir (Flow_In) and the volume of water in the reservoir (Res_Vol) for the Upper Navet Reservoir

\begin{tabular}{|c|c|c|c|c|c|}
\hline & \multicolumn{2}{|l|}{ Flow_In } & \multicolumn{2}{|l|}{ Res_Vol } & \multirow{2}{*}{$\begin{array}{l}\text { Res_Vol } \\
\text { 2nd validation } \\
\text { (2001-2010) }\end{array}$} \\
\hline & $\begin{array}{l}\text { Calibration } \\
\text { (1984-1990) }\end{array}$ & $\begin{array}{l}\text { Validation (1992, } \\
\text { 1993, 1995) }\end{array}$ & $\begin{array}{l}\text { Calibration } \\
(1984-1993)\end{array}$ & $\begin{array}{l}\text { Validation } \\
\text { (1994-2000) }\end{array}$ & \\
\hline$R^{2}$ & 0.89 & 0.91 & 0.70 & 0.72 & 0.73 \\
\hline NSE & $0.84^{*}$ & $0.81 *$ & 0.67 & 0.70 & 0.71 \\
\hline PBAIS & -11.40 & -22.80 & $-1.50 *$ & $0.00 *$ & $3.50 *$ \\
\hline RSR & $0.40 *$ & $0.43 *$ & 0.57 & 0.55 & 0.54 \\
\hline$P$-factor & 0.42 & 0.31 & 0.71 & 0.80 & 0.60 \\
\hline$R$-factor & 0.43 & 0.46 & 0.65 & 0.64 & 1.21 \\
\hline
\end{tabular}

"Very Good" represented by bold and *; "Good" represented by bold; and Satisfactory represented by Italics
For Res_Vol, the second variable calibrated, via visual observation, the simulated reservoir volume lagged the observed volume, by one month. Addressing this issue, the observed time series was set one month in advance, which resulted in the model statistics values falling within acceptable ranges (Table 4). It was found that after the calibration the reservoir volume was very well simulated $\left(R^{2}=0.70, \mathrm{NSE}=0.67\right)$. The model error index indicated a small model error in the simulated Res_Vol, based on the PBIAS and RSR values, -1.50 and 0.57, respectively. As for the uncertainty, based on 95PPU, the $P$-factor was 0.71 and the $R$-factor was 0.65 . The results presented in Fig. $2 \mathrm{~b}$ show the simulated and observed Res_Vol for the reservoir calibration period, 1984-1993 and validation period 1994-2000, together with the model's uncertainty. For the validation, $R^{2}$ was acceptable $\left(R^{2}=0.72\right)$, the simulated data fit the observed data well (NSE $=0.70)$, the simulated Res_Vol was not over or under estimate compared to the observed volume (PBIAS $=0.00$ ), the performance of the model was good $(\mathrm{RSR}=0.55)$, the $P$-factor was 0.80 and $R$-factor was 0.64 . Abbaspour (2015) stated for the $P$ - and $R$-factors no fixed numbers exist, but we acknowledge that the results should capture most of the observations with a small uncertainty. Therefore, for Res_Vol, based on the model performance and error indices, our results suggest that the $P$ - and $R$-factors values are acceptable.

Additionally, the 2nd validation during 2001-2010 provides support that the model was able to capture the reservoir volume at the Navet Reservoir, under the scenario of an increased water demand and different amount of water entering the reservoir, via the point source. The results showed that for the Navet hydrological model, for the 2 nd validation, the simulated reservoir volume was well simulated (Table 4 ), $60 \%$ of the measured data lie within 95PPU (P-factor $=0.60$ ) with a larger uncertainty $(R$-factor $=1.21)$, with graphical representation in Fig. 2c.

In this study, the sensitive parameters for the reservoir Flow_In were also deemed high ranking in other studies such as Alipour and Hosseini [46], Nilwar and Waikar [45] and Thavhana et al. [52]. Changes were made within the soil, groundwater and the channel parameters which reduced the uncertainty of the model output. In the absence of required data for the calibration and validation phases of the Navet hydrological model, statistical relationships based on existing data satisfactory estimated the reservoir volume. Firstly, a relationship was developed using the multiple regression model to estimate the volume of water flowing into the reservoir via streams. After the modifications of the Flow_In sensitive parameters, especially, $\mathrm{CH} \_\mathrm{K} 2$ and $\mathrm{CH}$ _N2, the model was able to describe the natural environment of the watershed, that is the general composition of the material at the bottom of a natural river. Secondly, a relationship between lake level and reservoir storage for Res_Vol was utilized, and while modifying Res_K only, the Navet hydrological model was able to satisfactorily estimate the volume of water flowing into the reservoir and the storage of water at the end of the month, for this small tropical watershed. In spite of the introduction of uncertainties in the weather data via the usage of datasets smaller than the recommended lengths for the weather generator, and using datasets outside the watershed under the assumption that the spatial variability was not large for temperature, relative humidity and solar radiation, the results obtained for the statistical criteria demonstrated that the model was able to reasonably describe the hydrological processes in the Navet Reservoir. Thus, this research shows that SWAT can be satisfactorily applied, with supporting evidence from the model performance statistics, to a small reservoir with limited input data for prediction of reservoir volume time and for water flowing into the reservoir. To the best of our knowledge, maybe for the first time the reservoir volume was calibrated and validated using SWAT for a small reservoir in a tropical region. Overall, the model has the ability to be utilized by water resources managers in understanding the watershed for the built conditions and model the impact of the future climate on the reservoir volume. It is 

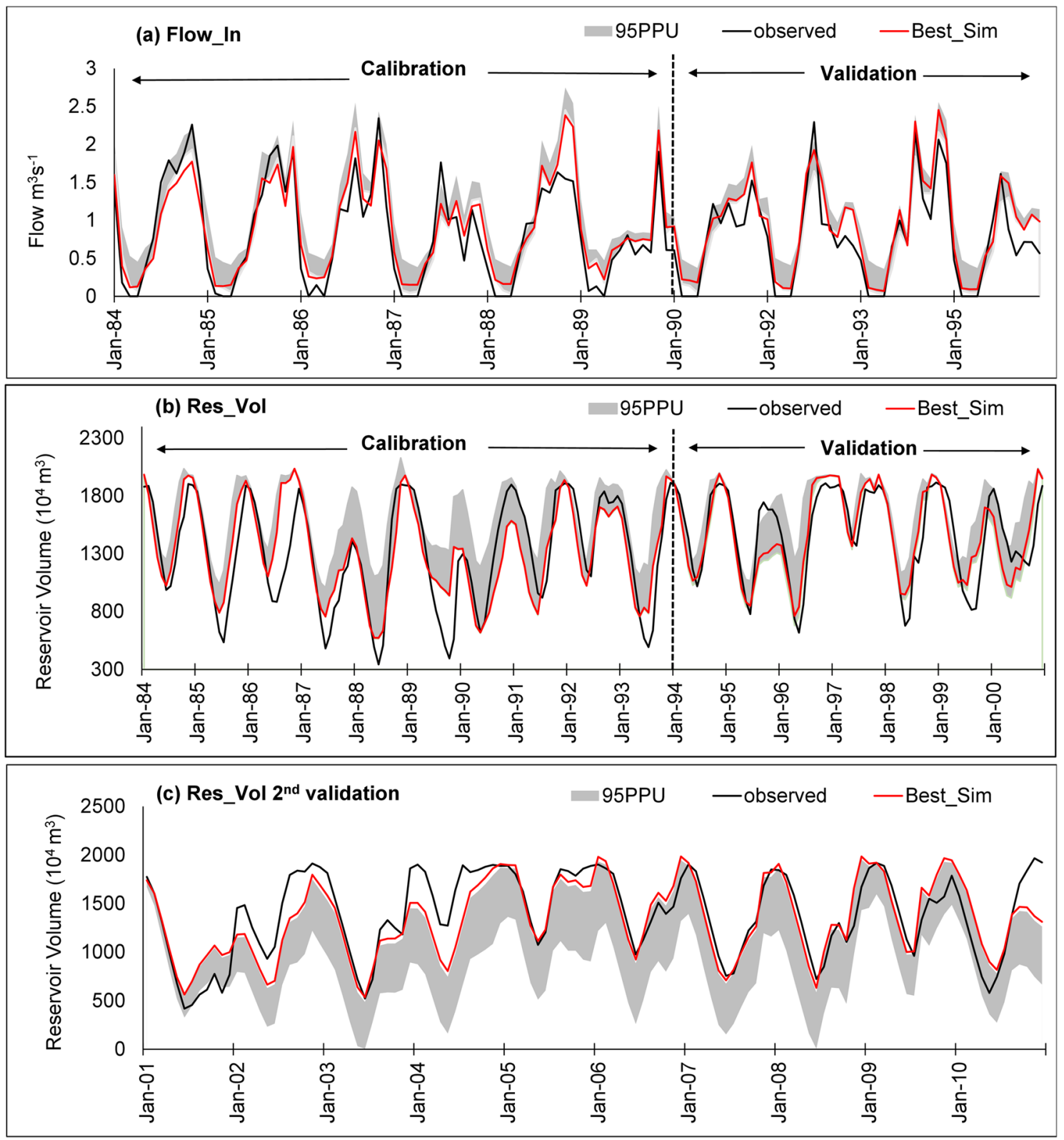

Fig. 2 Calibration and validation: comparison of the monthly observed and simulated a Flow_In, b the reservoir volume (Res Vol), and c a second validation of Res_Vol, together with the $95 \%$

noted that the model's estimation would be more accurate and the uncertainties smaller, with a better quality of input data. Therefore, we recommend that hydro-meteorological in-situ data be recorded and maintained in the watershed to improve the data quality and hence reduce the data input uncertainties. Additionally, this approach utilizing SWAT for the small island tropical watershed in Trinidad may be adopted and modified for other small watersheds within the island, within the Caribbean and other tropical regions, to model the hydrology of small reservoirs. prediction uncertainty (95PPU) in the grey band. The statistical performance of these figures is presented in Table 4

\section{Conclusion}

The model was calibrated and validated, for a 17-year period, 1984-2000, with Res_Vol being further validated for 2001-2010. Two variables Flow_In and Res_Vol were considered for the calibration of the Navet hydrological model. Within the calibration process, the most sensitive parameters were found to be ESCO, ALPHA_BNK, CH_K2, GW_DELAY, ALPHA_BF, and $\mathrm{CH}$ _N2. These parameters were modified to achieve the best model performance of the Flow_In, which in the calibration phase, based on the comparison of the 
observed and simulated data, was very good while the error indices were good and very good. Within the calibration of Res_Vol, the only parameter modified was Res_K which resulted in good performance, when the observed and simulated data were compared. The model also produced results within the acceptable range, for the error index indicating a slight over prediction of the Res_Vol.

As the validation phase, for Flow_In the comparison of observed and simulated statistics were acceptable and very good, while, the error indices results were satisfactory, suggesting an over prediction. For the estimation of Res_Vol, the model performance based on the statistics varied between good and very good. In the additional validation under the condition of increased water removal amounts, the model produced similar results as the first validation.

In the absence of required data, the application of statistical relationships utilizing existing data provided acceptable model outputs for the reservoir volume and water flowing into the reservoir. Overall, despite uncertainties introduced with the input data, such as the estimated data based on statistical relationships and within the weather data, the established Navet hydrological model was able to reasonably capture the Res_Vol, in the Upper Navet watershed in Trinidad during a 27-year period, 1984-2010. Thus, confirming the applicability of the SWAT model to predict flow in and reservoir volume for a small reservoir in the Caribbean island of Trinidad. The model may therefore serve as a possible tool to guide water resource managers on reservoir volume and the approach may be adopted and modified for similar circumstances.

Acknowledgements We would like to acknowledge and thank the following local agencies for making datasets available; the Surveys and Mapping Division of the Ministry of Agriculture, Land and Fisheries, Trinidad and Tobago, the Water Resources Agency of Trinidad and Tobago (WRA), the Meteorological Service of Trinidad and Tobago (MET) and the University of the West Indies (UWI), St Augustine Campus. This research did not receive any specific grant from funding agencies in the public, commercial, or not-for-profit sectors.

\section{Compliance with ethical standards}

Conflict of interest The authors declare that they have no known competing financial interests or personal relationships that could have appeared to influence the work reported in this paper.

Open Access This article is licensed under a Creative Commons Attribution 4.0 International License, which permits use, sharing, adaptation, distribution and reproduction in any medium or format, as long as you give appropriate credit to the original author(s) and the source, provide a link to the Creative Commons licence, and indicate if changes were made. The images or other third party material in this article are included in the article's Creative Commons licence, unless indicated otherwise in a credit line to the material. If material is not included in the article's Creative Commons licence and your intended use is not permitted by statutory regulation or exceeds the permitted use, you will need to obtain permission directly from the copyright holder. To view a copy of this licence, visit http://creativecommons .org/licenses/by/4.0/.

\section{References}

1. UN Water (2019) World Water Development Report 2019. https ://www.unwater.org/publications/world-water-developmen t-report-2019/\#print_all Accessed 14 Mar 2020

2. Nurse LA, McLean RF, Agard J, Briguglio LP, Duvat-Magnan, $V$, Pelesikoti N, Tompkins E, Webb A (2014) Small islands. In: Change Barros VR, Field CB, Dokken DJ, Mastrandrea MD, Mach KJ, Bilir TE, Chatterjee M, Ebi KL, Estrada YO, Genova RC, Girma B, Kissel ES, Levy AN, MacCracken S, Mastrandrea PR, White LL (eds) Climate change 2014: impacts, adaptation, and vulnerability. Part B: regional aspects. Contribution of working group II to the fifth assessment report of the intergovernmental panel on climate. Cambridge University Press, Cambridge, pp 1613-1654

3. Cashman A (2013) Water security and services in the Caribbean. Technical Note No. IDB-TN-514. https://publications.iadb.org/ publications/english/document/Water-Security-and-Servicesin-The-Caribbean.pdf. Accessed 18 May 2020

4. Campbell JD, Taylor MA, Stephenson TS, Watson RA, Whyte FS (2011) Future climate of the Caribbean from a regional climate model. Int J Climatol 31:1866-1878. https://doi.org/10.1002/ joc.2200

5. McLean NM, Stephenson TS, Taylor MA, Campbell JD (2015) Characterization of future Caribbean rainfall and temperature extremes across rainfall zones. Adv Meteorol 9:1-18. https://doi. org/10.1155/2015/425987

6. Dubey SK, Sharma D, Babel MS, Mundetia N (2020) Application of hydrological model for assessment of water security using multi-model ensemble of CORDEX-South Asia experiments in a semi-arid river basin of India. Ecol Eng 143:105641. https://doi. org/10.1016/j.ecoleng.2019.105641

7. Momiyama S, SagehashiAkiba MM (2020) Assessment of the climate change risks for inflow into Sagami Dam reservoir using a hydrological model. J Water Clim Change 11(2):367-379. https ://doi.org/10.2166/wcc.2018.256

8. Emami F, Koch M (2019) Modeling the impact of climate change on water availability in the Zarrine River Basin and inflow to the Boukan Dam, Iran. Climate 7(4):51. https://doi.org/10.3390/cli70 40051

9. Muhammad B, Babel MS, Shrestha S, Kawasaki A, Tripathi NK (2016) Assessment of climate change impact on reservoir inflows using multi climate-models under RCPs-the case of Mangla Dam in Pakistan. Water 8(9):389. https://doi. org/10.3390/w8090389

10. Zhang H, Huang GH, Wang D, Zhang X (2011) Uncertainty assessment of climate change impacts on the hydrology of small prairie wetlands. J Hydrol 396(1):94-103. https://doi. org/10.1016/j.jhydrol.2010.10.037

11. Bisson R (2002) Hydrogeological reassessment of trinidad volume I-chapters 1-4. Groundwater Assessment Well Dev Program Trinidad. https://doi.org/10.13140/RG.2.1.1364.3604

12. World Meteorological Organization (WMO) (2013) Weather, climate and water. RA IV-CHY expert meeting on water resources assessment, Panama City, Panama 5-7 March 2013. http://www. wmo.int/pages/prog/hwrp/documents/RAIV/RAIV-CHy-WRA2013-en.pdf. Accessed 14 Mar 2020.

13. Neitsch SL, Arnold JG, Kiniry JR, Williams JR (2011) Soil and water assessment tool theoretical documentation version 2009. Texas Water Resources Institute. http://hdl.handle.net/1969.1/128050

14. Zanin PR, Bonuma NB, Corseuil CW (2018) Hydrosedimentological modeling with SWAT using multi-site calibration in 
nested basins with reservoirs. Braz J Water Resour. https://doi. org/10.1590/2318-0331.231820170153

15. Carvalho-Santos C, Monteiro AT, Azevedo JC, Honrado JP, Nunes JP (2017) Climate change impacts on water resources and reservoir management: uncertainty and adaptation for a mountain catchment in Northeast Portugal. Water Resour Manag 31:33553370. https://doi.org/10.1007/s11269-017-1672-z

16. Wu Y, Chen J (2012) An operation-based scheme for a multiyear and multipurpose reservoir to enhance macroscale hydrologic models. J Hydrometeorol 13(1):270-283. https://doi. org/10.1175/JHM-D-10-05028.1

17. Vale M, Holman IP (2009) Understanding the hydrological functioning of a shallow lake system within a coastal karstic aquifer in Wales UK. J Hydrol 376(1-2):285-294. https://doi. org/10.1016/j.jhydrol.2009.07.041

18. Cashman A (2014) Water security and services in the Caribbean. Water 6:1187-1203. https://doi.org/10.3390/w6051187

19. Quesada-Montano B, Wetterhall F, Westerberg IK, Hidalgo HG, Halldin S (2019) Characterising droughts in Central America with uncertain hydro-meteorological data. Theor Appl Climatol 137:2125-2138. https://doi.org/10.1007/s00704-018-2730-z

20. Remesan R, Holman IP (2015) Effect of baseline meteorological data selection on hydrological modelling of climate change scenarios. J Hydrol 528:631-642. https://doi.org/10.1016/j.jhydr ol.2015.06.026

21. Dile YT, Srinivasan R (2014) Evaluation of CFSR climate data for hydrologic prediction in data-scarce watersheds: an application in the Blue Nile River Basin. J Am Water Resour Assoc (JAWRA) 50(5):1226-1241. https://doi.org/10.1111/jawr.12182

22. Mengistu AG, van Rensburg LD, Woyessa YE (2019) Techniques for calibration and validation of SWAT model in data scarce arid and semi-arid catchments in South Africa. J Hydrol Reg Stud 25:100621. https://doi.org/10.1016/j.ejrh.2019.100621

23. Water and Sewerage Authority of Trinidad and Tobago (WASA) (1990) Explanatory notes: hydrogeological maps of Trinidad and Tobago

24. Trinidad and Tobago Meteorological Services (MET) (2019) Climate: Trinidad and Tobago. http://metoffice.gov.tt/Climate. Accessed 2 Apr 2019

25. Water and Sewerage Authority of Trinidad and Tobago (WASA) (1975) Climatic data report 1975

26. Environmental Management Authority (EMA) (1998) Trinidad and Tobago state of the environment 1998 report. https:// wedocs.unep.org/rest/bitstreams/16008/retrieve. Accessed 14 Mar 2020

27. Water and Sewerage Authority of Trinidad and Tobago (WASA) (2008) Navet reservoir. https://www.wasa.gov.tt/WASA_Educa tion_water_Reservoir_Navet.html. Accessed 14 Mar 2020

28. Winchell M, Srinivasan R, Di Luzio M, Arnold JG (2013) Arcswat Interface for SWAT2012: User's Guide. Blackland Research Center, Texas AgriLife Research, College Station, pp 1-464

29. Liu J, Williams JR, Wang X, Yang H (2009) Using MODAWEC to generate daily weather data for the EPIC model. Environ Modell Softw 24(5):655-664. https://doi.org/10.1016/j.envso $\mathrm{ft} .2008 .10 .008$

30. Mahabir R, Al-Tahir R (2008) The role of spatial data infrastructure in the management of land degradation in small tropical Caribbean Islands. In: 10th International conference for spatial data infrastructure. University of the West Indies - St. Augustine, Port of Spain, Trinidad, from 25 to 29 February 2008

31. Abbaspour KC, Vaghefi SA, Srinivasan R (2018) A guideline for successful calibration and uncertainty analysis for soil and water assessment: a review of papers from the 2016 international SWAT conference. Water. https://doi.org/10.3390/w10010006

32. Yang Y, Wang G, Wang L, Yu J, Xu Z (2014) Evaluation of gridded precipitation data for driving SWAT model in area upstream of three gorges reservoir. PLoS ONE. https://doi.org/10.1371/journ al.pone. 0112725

33. Goyal MK, Madramootoo CA, Richards JF (2015) Simulation of the Streamflow for the Rio Nuevo Watershed of Jamaica for use in agriculture water scarcity planning. J Irrig Drain Eng. https://doi.org/10.1061/(ASCE)IR.1943-4774.0000802

34. Montecelos-Zamora Y, Cavazos T, Kretzschmar T, Vivoni ER, Corzo G, Molina-Navarro E (2018) Hydrological modeling of climate change impacts in a tropical river basin: a case study of the Cauto River Cuba. Water (Switzerland). https://doi. org/10.3390/w10091135

35. Fukunaga CD, Cecilio RA, Zanetti SS, Oliveira LT, Caiado AAC (2015) Application of the SWAT hydrologic model to a tropical watershed at Brazil. CATENA 125:206-213. https://doi. org/10.1016/j.catena.2014.10.032

36. Leta OT, El-Kadi A, Dulai H, Ghazal KA (2016) Assessment of climate change impacts on water balance components of Heeia watershed in Hawaii. J Hydrol Reg Stud 8:182-197. https://doi. org/10.1016/j.ejrh.2016.09.006

37. $\mathrm{Wu} \mathrm{H}$, Chen $\mathrm{B}$ (2015) Evaluating uncertainty estimates in distributed hydrological modeling for the Wenjing River watershed in China by GLUE, SUFI-2, and ParaSol methods. Ecol Eng 76:110-121. https://doi.org/10.1016/j.ecoleng.2014.05.014

38. Molina-Navarro E, Hallack-Alegría M, Martínez-Pérez $S$, Ramírez-Hernández J, Mungaray-Moctezuma A, Sastre-Merlín A (2016) Hydrological modeling and climate change impacts in an agricultural semiarid region. Case study: Guadalupe River Basin, Mexico. Agric Water Manag 175:29-42. https:// doi.org/10.1016/j.agwat.2015.10.029

39. Abbaspour KC (2015) SWAT-CUP: SWAT calibration and uncertainty programs- a user manual, department of systems analysis, integrated assessment and modelling (SIAM), EAWAG. Swiss Federal Institute of Aqualtic Science and Technology, Duebendorf, Switzerland." User Manual, p 100. doi:https://doi. org/10.1007/s00402-009-1032-4

40. Moriasi DN, Arnold JG, Van Liew MW, Bingner RL, Harmel RD, Veith TL (2007) Model evaluation guidelines for systematic quantification of accuracy in watershed simulations. Trans ASABE 50(3):885-900. https://doi.org/10.13031/2013.23153

41. Khayyun TS, Alwan IA, Hayder AM (2019) Hydrological model for Hemren dam reservoir catchment area at the middle River Diyala reach in Iraq using ArcSWAT model. Appl Water Sci 9:133. https://doi.org/10.1007/s13201-019-1010-0

42. Setegn SG, Melesse AM, Haiduk A, Webber D, Wang X, McClain ME (2014) Modeling hydrological variability of fresh water resources in the Rio Cobre Watershed, Jamaica. CATENA 120:81-90. https://doi.org/10.1016/j.catena.2014.04.005

43. Ghoraba SM (2015) Hydrological modeling of the Simly Dam watershed (Pakistan) using GIS and SWAT model. Alex Eng J 54(3):583-594. https://doi.org/10.1016/j.aej.2015.05.018

44. Das B, Jain S, Singh S, Thakur P (2019) Evaluation of multisite performance of SWAT model in the Gomti River Basin India. Appl Water Sci 9(5):1-10. https://doi.org/10.1007/s1320 1-019-1013-x

45. Nilawar AP, Waikar ML (2018) Use of SWAT to determine the effects of climate and land use changes on streamflow and sediment concentration in the Purna River Basin India. Environ Earth Sci. https://doi.org/10.1007/s12665-018-7975-4

46. Alipour M, Hosseini $M$ (2018) Simulation of surface runoff in Karaj Dam Basin Iran. Appl Water Sci 8(5):1-10. https://doi. org/10.1007/s13201-018-0782-y

47. Santhi C, Arnold JG, Williams JR, Dugas WA, Srinivasan R, Hauck LM (2001) Validation of the SWAT model on a large river basin aith point and nonpoint sources. J Am Water Resour Assoc 37(5):1169-1188. https://doi.org/10.1111/j.1752-1688.2001. tb03630.x 
48. Gupta HV, Sorooshian S, Yapo PO (1999) Status of automatic calibration for hydrologic models: comparison with multilevel expert calibration. J Hydrol Eng 4(2):135-143. https://doi. org/10.1061/(ASCE)1084-0699(1999)4:2(135)

49. Arnold JG, Kiniry JR, Srinivasan R, Williams JR, Haney EB, Neitsch SL (2012) SWAT 2012 Input/output documentation. Texas Water Resources Institute. Available electronically from http:// hdl.handle.net/1969.1/149194

50. Kaffas K, Hrissanthou V, Sevastas S (2018) Modeling hydromorphological processes in a mountainous basin using a composite mathematical model and ArcSWAT. CATENA 162:108-129. https ://doi.org/10.1016/j.catena.2017.11.017
51. Abbaspour KC, Rouholahnejad E, Vaghefi S, Srinivasan R, Yang $\mathrm{H}$, Kløve B (2015) A continental-scale hydrology and water quality model for Europe: Calibration and uncertainty of a high-resolution large-scale SWAT model. J Hydrol 524:733-752. https://doi. org/10.1016/j.jhydrol.2015.03.027

52. Thavhana MP, Savage MJ, Moeletsi ME (2018) SWAT model uncertainty analysis, calibration and validation for runoff simulation in the Luvuvhu River catchment, South Africa. Phys Chem Earth 105:115-124. https://doi.org/10.1016/j.pce.2018.03.012

Publisher's Note Springer Nature remains neutral with regard to jurisdictional claims in published maps and institutional affiliations. 